OPEN ACCESS

Edited by: Annalisa Del Prete,

University of Brescia, Italy

Reviewed by:

Silvia Gregori,

Istituto San Raffaele Telethon per la Terapia Genica (SR-Tiget), Italy

Raymond P. Donnelly,

United States Food and Drug

Administration, United States

*Correspondence:

Giorgio Raimondi

g.raimondi@jhmi.edu

Specialty section:

This article was submitted

to Cytokines and Soluble

Mediators in Immunity,

a section of the journal

Frontiers in Immunology

Received: 01 February 2018

Accepted: 25 June 2018

Published: 16 July 2018

Citation:

Iglesias M, Arun A, Chicco M, Lam B,

Talbot CC Jr., Ivanova V, Lee WPA, Brandacher $G$ and Raimondi $G$ (2018) Type-I Interferons Inhibit Interleukin-10 Signaling and Favor

Type 1 Diabetes Development in Nonobese Diabetic Mice.

Front. Immunol. 9:1565. doi: 10.3389/fimmu.2018.01565

\section{Type-I Interferons Inhibit Interleukin-10 Signaling and Favor Type 1 Diabetes Development in Nonobese Diabetic Mice}

\author{
Marcos Iglesias ${ }^{1}$, Anirudh Arun 1, Maria Chicco', Brandon Lam ${ }^{1}$, C. Conover Talbot Jr.2, \\ Vera Ivanova ${ }^{1}$, W. P. A. Lee ${ }^{1}$, Gerald Brandacher ${ }^{1}$ and Giorgio Raimondi ${ }^{1 *}$ \\ ${ }^{\top}$ Vascularized and Composite Allotransplantation Laboratory, Department of Plastic and Reconstructive Surgery, Johns \\ Hopkins School of Medicine, Baltimore, MD, United States, ${ }^{2}$ Institute for Basic Biomedical Sciences, Johns Hopkins School \\ of Medicine, Baltimore, MD, United States
}

Destruction of insulin-producing $\beta$-cells by autoreactive $T$ lymphocytes leads to the development of type 1 diabetes. Type-I interferons (TI-IFN) and interleukin-10 (IL-10) have been connected with the pathophysiology of this disease; however, their interplay in the modulation of diabetogenic T cells remains unknown. We have discovered that TI-IFN cause a selective inhibition of IL-10 signaling in effector and regulatory T cells, altering their responses. This correlates with diabetes development in nonobese diabetic mice, where the inhibition is also spatially localized to $T$ cells of pancreatic and mesenteric lymph nodes. IL-10 signaling inhibition is reversible and can be restored via blockade of TI-IFN/IFN-R interaction, paralleling with the resulting delay in diabetes onset and reduced severity. Overall, we propose a novel molecular link between TI-IFN and IL-10 signaling that helps better understand the complex dynamics of autoimmune diabetes development and reveals new strategies of intervention.

Keywords: type-I interferons, interleukin-10 signaling, T lymphocytes, type 1 diabetes, nonobese diabetic mice

\section{INTRODUCTION}

Type 1 diabetes is a complex autoimmune disease characterized by the progressive destruction of the insulin-producing $\beta$-cells in the pancreas by autoreactive T lymphocytes (1). It is caused by a combination of genetic predisposition and environmental factors. In the past decade, viral infections and the composition of the gut microbiota have gained increasing attention as environmental factors that contribute to the initiation of the disease (2-4) but the mechanisms by which these factors contribute to the activity of diabetogenic T cells remains unknown. It is clear that CD4 T cells are of chief importance in this disease. Nonobese diabetic (NOD) mice, a widely used model of human disease that spontaneously develop diabetes, are protected from the disease onset when deficient in $\mathrm{CD} 4 \mathrm{~T}$ cells $(5,6)$, and enriched $\mathrm{CD} 4^{+}$cells from diabetic donors are able to transfer the disease when administered into NOD-scid/scid recipients (7). However, the connection between environment and the activity of diabetogenic $\mathrm{T}$ cells remains elusive.

Abbreviations: ALN, axillary lymph nodes; IL-10, interleukin-10; MFI, mean fluorescence intensity; MLN, mesentheric lymph nodes; NOD, nonobese diabetic; PLN, pancreatic lymph nodes; TI-IFN, type-I interferons; Tmem, memory T cells; Tregs, regulatory $\mathrm{T}$ cells. 
Multiple clinical and experimental observations point toward type-I interferons (TI-IFNs), essential cytokines for the clearance of viruses, as the mediators that drive a pre-diabetic or susceptible individual toward type 1 diabetes (8). Relevant examples include high levels of IFN- $\alpha$ detected in the pancreas of diabetic patients (9), absence of autoantibodies able to neutralize IFN- $\alpha$ in the subset of AIRE-deficient (APS1) patients who developed diabetes (10), induction of diabetes in non-autoimmune prone C57BL/ 6 mice by overexpression of IFN- $\alpha$ in $\beta$-cells (11), accumulation of high levels of TI-IFN in NOD mice (12), and delay of disease onset (and decreased incidence) with early blockade of TI-IFN receptor signaling (13). More recently, Ferreira and colleagues reported that an IFN signature in PBMC of genetically predisposed children was detectable before the appearance of islet-specific autoantibodies (14). Despite these observations, the mechanism(s) through which TI-IFN promotes T1D remains poorly understood.

The cytokine interleukin-10 (IL-10) has an essential role in the development of autoimmune pathologies (15). Previous studies suggested that the low expression of this cytokine in the pancreas mediates the occurrence of diabetes (16) and decreased IL-10 levels in serum of newly diagnosed children with type 1 diabetes has been observed (17). Monocytes/macrophages have been historically investigated as the main target of this cytokine (18); however, IL-10 acts also directly on $\mathrm{T}$ cells. This has been shown in the context of naive $\mathrm{T}$ cells activation and differentiation $(19,20)$, in the regulation of effector and memory T cells (Tmem) (21-23), and in the preservation of regulatory T cell (Treg) function $(24,25)$.

Here, we report a novel effect of TI-IFN that causes a selective inhibition of IL-10 signaling in T cells thereby reducing their capacity to be regulated. This loss of signaling correlates with the development of the disease in NOD mice. This effect is sustained but compartmentalized, manifesting only in T cells of pancreatic lymph nodes (PLN) and mesenteric lymph nodes (MLN) of NOD mice, suggesting a link with the response to the gastric environment in these animals. Importantly, IL-10 signaling in T cells could be partially restored via blockade of TI-IFN signaling, supporting earlier observations on the beneficial effects of transient TI-IFN blockade in NOD mice (13). Overall, our results reveal a new molecular mechanism involved in the causative process of type 1 diabetes and suggest novel targets for its prevention and treatment.

\section{MATERIALS AND METHODS}

\section{Mice}

Nonobese diabetic, wt C57BL/6 (B6), C57BL/6-Foxp3-GFP, IFN-AR1 ${ }^{-1-}$, and $\mathrm{Rag}^{-/-}$mice were purchased from Jackson Laboratories, and bred at the Johns Hopkins School of Medicine facility. All animal experiments were conducted in accordance with the National Institutes of Health guide for use and care of laboratory animals, and under a protocol approved by the JHU Animal Care and Use Committee.

\section{Media, Reagents, and Antibodies}

RPMI-1640 and IMDM media were supplemented with 10\% v/v heat-inactivated FCS (Atlanta Biologicals, Flowery Branch, GA,
USA), $0.1 \mathrm{mM}$ non-essential amino acids, $2 \mathrm{mM}$ L-glutamine, sodium pyruvate, $100 \mathrm{IU} / \mathrm{ml}$ penicillin, $100 \mu \mathrm{g} / \mathrm{ml}$ streptomycin, and $50 \mu \mathrm{M} 2-\mathrm{ME}$ (Gibco). Recombinant IFN- $\beta$ and IFN- $\alpha$ were purchased from PBL Assay Science. Blocking anti-IFN-AR1 mAb was from Leinco Technologies (St. Louis, MO, USA). Recombinant IL-10 and IL-6 were from PeproTech (Rocky Hill, NJ, USA). Jak inhibitors Tofacitinib and Ruxolitinib were purchased from LC Laboratories (Woburn, MA, USA).

\section{T Cell (Subsets) Isolation}

Spleen and lymph nodes were harvested and total/CD4 T cells were isolated via magnetic-bead negative selection. Briefly, cells were incubated with anti-mouse Ter119 (TER-119), Gr1 (RB6-85C), CD11b (M1/70), B220 (RA3-6B2), CD16/32 (2.462), I-A/I-E (M5/114.15.2) [also anti-CD8 (53-6.7) for CD4 T cell purification] (all from BD Biosciences) followed by incubation with magnetic beads conjugated with anti-rat IgG (ThermoFisher) at a 1:1 (cell:bead) ratio. The resulting total/CD4 $\mathrm{T}$ cells were $>90 \%$ pure. Where indicated, Treg $\left(\mathrm{CD} 4{ }^{+} \mathrm{CD} 25^{+}\right)$were isolated from CD4 T cells following the protocol described in the EasySep PE-selection kit (STEMCELL technologies).

\section{CD4 Tmem Generation}

In some experiments, Tmem were generated via a modification of the published "parking method" (26). Briefly, $20 \times 10^{7}$ $\mathrm{T}$ cells from B6 mice were activated with anti-CD3 $(0.5 \mu \mathrm{g} / \mathrm{ml}$; BD Pharmingen) in the presence of syngeneic LPS-matured bone marrow-derived DCs (1:20 ratio DC:T cell) as previously described (27). Three days later, activated $\mathrm{T}$ cells together with $10^{7} \mathrm{~T}$ cell-depleted splenocytes [obtained via removal of $\mathrm{CD}^{+}$ cells from single cell suspensions using the protocol described in Section “T Cell (Subsets) Isolation"] were infused intravenously into $\mathrm{Rag}^{-/-}$mice. Four weeks later, Tmem were isolated and used for the indicated experiments.

\section{Cell Stimulation and Preparation for Phospho-Flow Analysis}

For assessment of proteins phosphorylation via flow cytometry (Phospho-flow), a modification of the protocol published by the Nolan group (28) was utilized. Briefly, $10-15 \times 10^{6}$ purified $\mathrm{T}$ cells were cultured in IMDM complete media with/without IFN- $\beta(1-25 \mathrm{ng} / \mathrm{ml})$ for indicated periods and then rested in cytokine-free media for six additional hours. $2 \times 10^{6} \mathrm{fresh} /$ cultured cells were stimulated for $20 \mathrm{~min}$ with IL-10 $(40 \mathrm{ng} / \mathrm{ml})$ or IL-6 (40 ng/ml), or $30 \mathrm{~min}$ with IFN- $\beta / \alpha(5 \mathrm{ng} / \mathrm{ml})$. Then, cells were fixed for $50 \mathrm{~min}$ by adding $2.4 \mathrm{ml}$ of a solution containing $4 \%$ paraformaldehyde and $1.4 \%$ methanol in PBS. After fixation, $600 \mu \mathrm{l}$ of $1 \times$ wash buffer (contained in the Transcription Factor Phospho Buffer Set kit, BD Biosciences) were added to the previous mixture, mixed, and spun down. Finally, cells were suspended with $500 \mu \mathrm{l}$ Perm Buffer III (BD Biosciences) while vortexing, and stored at $-20^{\circ} \mathrm{C}$ until use.

\section{Flow Cytometry and Cell Sorting}

In Phospho-flow experiments, Perm Buffer III was removed and cells stained with fluorchrome-labeled antibodies against CD4 (RM4-5), CD44 (IM7), Foxp3 (FJK-1) (Thermo Fisher 
eBioscience), and Stat3 (pY705) (4/P_STAT3; BD Phospho-flow). For IL-10R staining, the Human IL-10 biotinylated Fluorokine kit (R\&D Systems) was used. Detection of suppressor of cytokine signaling protein (SOCS)1 and SOCS3 mRNA levels via flow cytometry was performed employing the PrimeFlow RNA assay kit (Thermo Fisher) following the manufacturer guidelines. Data were acquired using an LSR-II flow cytometer (BD Biosystems) and analyzed with FlowJo X version software (FLOWJO, LLC, Ashland, OR, USA). For WB and qPCR experiments using T cell subpopulations, fresh or cultured T cells were stained with CD4 (RM4-5), CD25 (PC61) (not in the case of cells from Foxp3-GFP mice), and CD44 (IM7) antibodies and the specific subsets of Tmem $\left(\mathrm{CD}^{+}{ }^{+} \mathrm{Foxp}^{-} \mathrm{CD}^{-} 4^{+}\right)$and Treg $\left(\mathrm{CD}^{+}{ }^{+} \mathrm{Foxp} 3 / \mathrm{GFP}^{+}\right.$or $\mathrm{CD} 4^{+} \mathrm{CD} 25^{+}$) were sorted to $99 \%$ purity using a FACS Aria II cell sorter.

\section{Western Blot}

Either total CD4 T cells or Tmem and Treg subpopulations after specific culture conditions were lysed with RIPA buffer containing proteases and phosphatases inhibitors. MG-132 (MilliporeSigma) was added for the last $1.5 \mathrm{~h}$ of culture in the experiments where SOCS protein levels were studied. Cell lysates were run in $10-12 \%$ acrylamide gels and proteins transferred to a PVDF membrane. Protein expression levels were detected with the following antibodies: phospho-STAT3 (Y705) (D3A7), SOCS1 (A156), SOCS3 (L210) (all from Cell Signaling Technology), and $\beta$-actin (I-19; Santa Cruz biotechnology). Protein expression was detected using fluorescent-labeled secondary antibodies (LI-COR). Data were acquired using an Odyssey CLx (LI-COR) imaging system and analyzed with ImageJ software to normalize values to $\beta$-actin levels.

\section{Quantitative Real-Time PCR}

CD4 T cells were lysed in TRIzol reagent (Thermo), and RNA was extracted using chloroform (Fisher Scientific) and the RNeasy MiniElute Cleanup Kit (Qiagen). The mRNA was reverse transcribed using the SuperScript IV First Strand Synthesis System and protocol (Thermo Scientific). Real-time RT-PCR was performed on a QuantiStudio 12K Flex Real-Time PCR system (Thermo Scientific) calibrated for SYBR Green detection. The primers and conditions employed are listed in Table S1 in Supplementary Material.

\section{Statistical Analysis}

Differences in flow cytometry quantification of P-STAT3-mean fluorescence intensity (MFI) were analyzed using either twosample Mann-Whitney $U$ test or two-tailed paired Student's $t$-test. To minimize the impact of fluctuations in fluorescence among experiments, the coefficient index (MFI P-STAT3 in stimulated cells/MFI P-STAT3 in unstimulated cells) was calculated and averaged for each experiment and then used for statistical analysis. P-STAT3 expression comparisons between $\mathrm{T}$ cells of NOD and B6 mice were analyzed using two-way ANOVA. Two-tailed unpaired Student's $t$-test was applied to test gene expression differences from PCR experiments. All analyses were performed with Prism Software version 5.0 (GraphPad, La Jolla, CA, USA).

\section{RESULTS}

\section{Localized Defective IL-10 Signaling in Memory and Regulatory CD4 T Cells in TI-IFN Enriched Tissues}

Li et al. reported unexpectedly high levels of IFN $\alpha$ production in the PLN of NOD mice starting in the second week of life that correlated with the presence of $\mathrm{CD} 4 \mathrm{~T}$ cells with a transcriptional signature abundant in INF-induced genes (13). We examined via qPCR the expression of different interferons transcripts (Figure S1 in Supplementary Material) and found that IFN- $\alpha$ (IFN $\alpha 4$ and IFN $\alpha 9$ ) but also IFN- $\beta 1$ mRNA levels were upregulated in PLN of 4-week-old NOD mice when compared to the levels found in the spleen. This upregulation was maintained at least until the $12^{\text {th }}$ week of life. Based on the suspected involvement of IL-10 in disease development, we tested if these TI-IFN-exposed $\mathrm{T}$ cells would show any alteration in their response to IL-10. To evaluate signal integrity, we quantified the accumulation of the phosphorylated (active) form of the transcription factor STAT3 (P-STAT3, a key molecule in the IL-10 signaling pathway) in response to ex vivo stimulation with IL-10. The response to the pro-inflammatory cytokine IL-6 (that also induces phosphorylation of STAT3) was measured to distinguish between cytokinespecific vs nonspecific effects of TI-IFN exposure. We compared multiple $\mathrm{CD} 4 \mathrm{~T}$ cell subsets: naïve $\left(\mathrm{CD} 4^{+} \mathrm{CD} 44^{\text {low }} \mathrm{Foxp}^{-}\right)$, memory $\left(\mathrm{CD} 4^{+} \mathrm{Foxp}^{-}{ }^{-} \mathrm{CD} 44^{\mathrm{hi}}\right)$, and regulatory $\left(\mathrm{CD} 4^{+} \mathrm{Foxp} 3^{+}\right)$ T cells residing in PLN, MLN, axillary lymph nodes (ALN), and spleen (each separately) in 4-week-old NOD mice-the time of highest accumulation of IFN $\alpha$ and IFN $\beta$ [(13) and our data]. Independent repeats of these measurements indicated a statistically significant reduction in IL-10 signaling in both Tmem and Treg from PLN and also from MLN compared to the response of the same $T$ cell subsets in the spleen (Figures 1A,B) and ALN (not shown). The reduced response in MLN paralleled the observed accumulation of TI-IFNs in these lymphoid tissues (Figure S1 in Supplementary Material). In 4-week-old non-diabetes prone B6 mice, which do not accumulate TI-IFN in pancreatic and mesenteric lymph nodes (Figure S1 in Supplementary Material), Tmem and Treg preserved their ability to fully respond to IL-10 in all lymphoid tissues (Figures 1A,B). Importantly, this decrement in STAT3 phosphorylation was specific to IL-10 signaling, as the response to IL- 6 was unaltered in the T cells of NOD (and B6) mice from all the lymphoid tissues tested (Figure 1C). Together, these results suggested that in NOD mice there is a selective reprogramming of the signaling for IL-10, actuated specifically in lymphoid tissues shown to accumulate TI-IFN (13).

\section{The Impact of TI-IFN on IL-10 Signaling Is Not a Genetic Characteristic of NOD T Cells}

We then tested whether this effect was unique to T cells of NOD background, or bystander exposure of any $\mathrm{T}$ cells to unusual levels of TI-IFN could affect their ability to be controlled by IL-10. Bulk T cells from wt B6 mice were exposed to IFN- $\beta$ or IFN- $\alpha$ for $48 \mathrm{~h}$, and then the levels of P-STAT3 induced by 
A

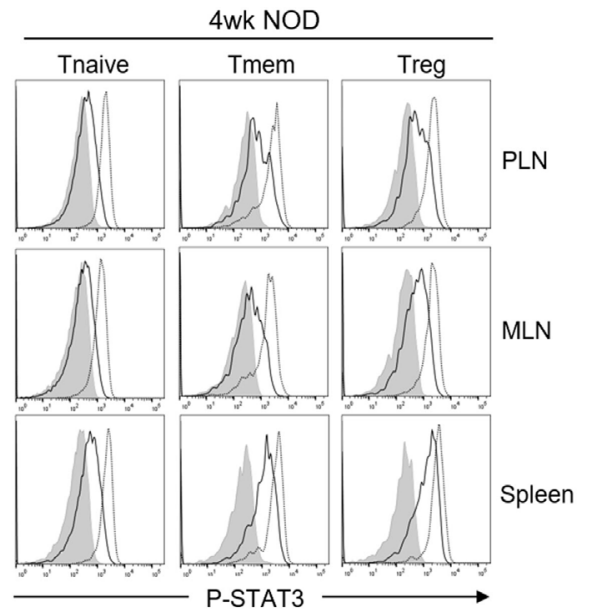

B

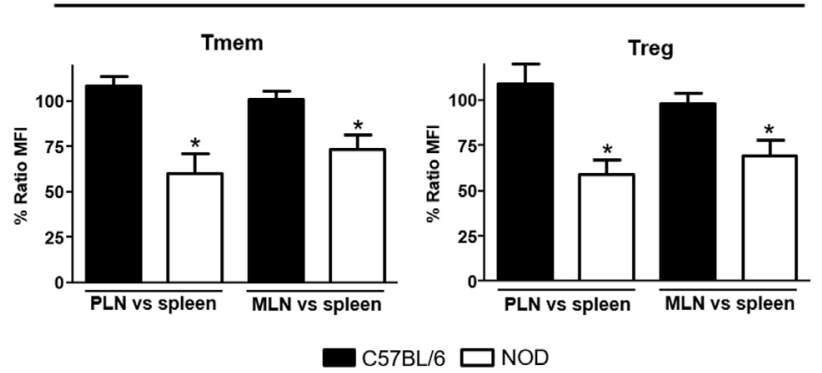

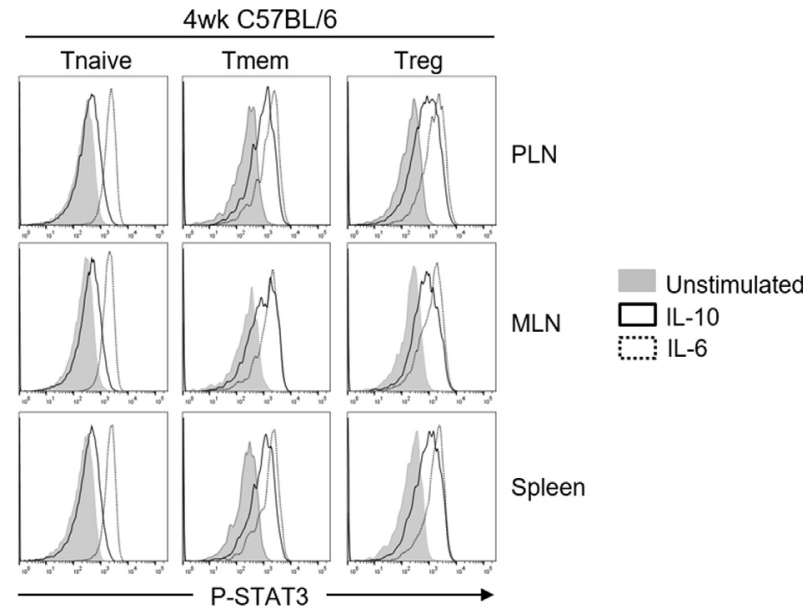

C

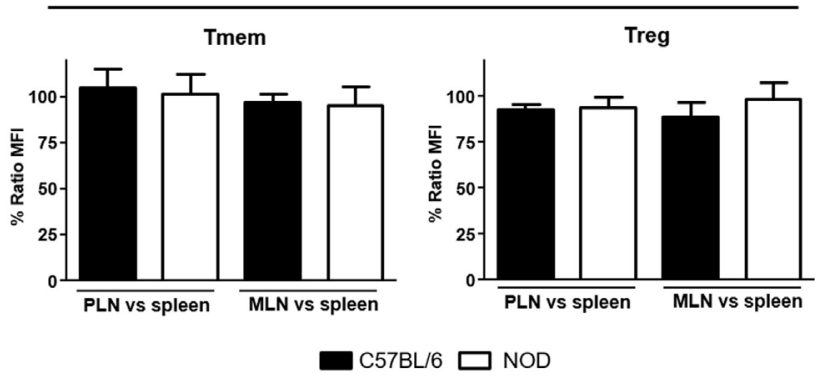

FIGURE 1 | Defective interleukin-10 (IL-10) signaling in memory T cells (Tmem) and regulatory T cells (Tregs) in pancreatic and mesenteric lymph nodes of nonobese diabetic (NOD) mice. Cells of pancreatic lymph nodes (PLN), mesenteric lymph nodes (MLN), and spleens of 4-week-old NOD or C57BL/6 mice were either left untreated or stimulated with IL-10 $(40 \mathrm{ng} / \mathrm{ml})$ or IL-6 $(40 \mathrm{ng} / \mathrm{ml})$ for $20 \mathrm{~min}$. Phosphorylated-STAT3 (P-STAT3) levels induced in CD4 T cell subpopulations (Tnaive: CD4+CD44lowFoxp3-, Tmem: CD4+CD44 ${ }^{\text {hiFoxp3- }}$, and Treg: CD4+Foxp3 ${ }^{+}$) were measured by Phospho-flow. (A) Representative histograms of P-STAT3 levels in the indicated CD4 T cell subpopulations after IL-10 and IL-6 stimulation. (B,C) Cumulative representation of the percentage of P-STAT3 signal induction in PLN/MLN Tmem and Treg after IL-10 (B) or IL-6 (C) stimulation compared to level induced in the splenic populations of the indicated mouse strain. This ratio of mean fluorescence intensities (MFIs) was calculated by comparing the coefficient index of P-STAT3 between two different tissues, considering the levels in spleen as 100\% of expression. Data shown in (B,C) are the average from $n=4$ mice per strain and are expressed as \% of ratio $\mathrm{MFI} \pm \mathrm{SEM},{ }^{*} p<0.05$, Mann-Whitney $U$ test.

stimulation with IL-10 or IL-6 were quantified via Phosphoflow. Exposure to IFN- $\beta$ induced a statistically significant reduction of STAT3 phosphorylation after IL-10 stimulation in Tmem and Tregs when compared to the response in fresh or mock-treated cells (cultured without IFN- $\beta$, to exclude any impact from the culturing conditions) (Figures 2A,B). These results were confirmed via western blot measurement of phospho-STAT3 levels (Figure 2D). Reduction of IL-10 signaling was IFN- $\beta$ dose-dependent, reaching maximum inhibition at $5 \mathrm{ng} / \mathrm{ml}$ of IFN- $\beta$ (Figure S2A in Supplementary Material). Exposure to IFN- $\alpha$ induced a similar inhibition of IL-10 signaling in a dose-dependent manner, though it required a higher concentration for maximal inhibition than IFN- $\beta$ (Figure S2B in Supplementary Material). As observed in T cells from NOD mice, the levels of P-STAT3 in response to IL-6 stimulation remained unaltered under all conditions (Figures 2A,C), confirming that this effect was not a generalized saturation of the Jak/STAT signaling pathway.

\section{IFN- $\beta$-Mediated Inhibition of IL-10 Signaling Alters Induction of IL-10 Responsive Genes}

A deeper evaluation of the functional impact that inhibition of IL-10 signaling by TI-IFN has on the modulation of T cells can be done via assessment of its transcriptional impact. However, the transcriptional impact of IL-10 on T cells is unknown. We therefore harnessed the vast knowledge about IL-10 signaling in antigen-presenting cells. Taking advantage of data from the most recent publicly available RNAseq analysis of mouse macrophages exposed to IL-10 (29), we selected a pool of 29 genes highly upregulated $(>6 \sigma)$ (Figure S3A in Supplementary Material) as initial lead for genes that could be also induced in T cells. Ten of these upregulated genes had known functions in $\mathrm{T}$ cells (Figure S3B in Supplementary Material). We then tested the expression of these genes as a screening panel for further investigation of Treg and Tmem cells responses to IL-10 with or without TI-IFN pre-exposure. To obtain a sufficient and homogeneous number 

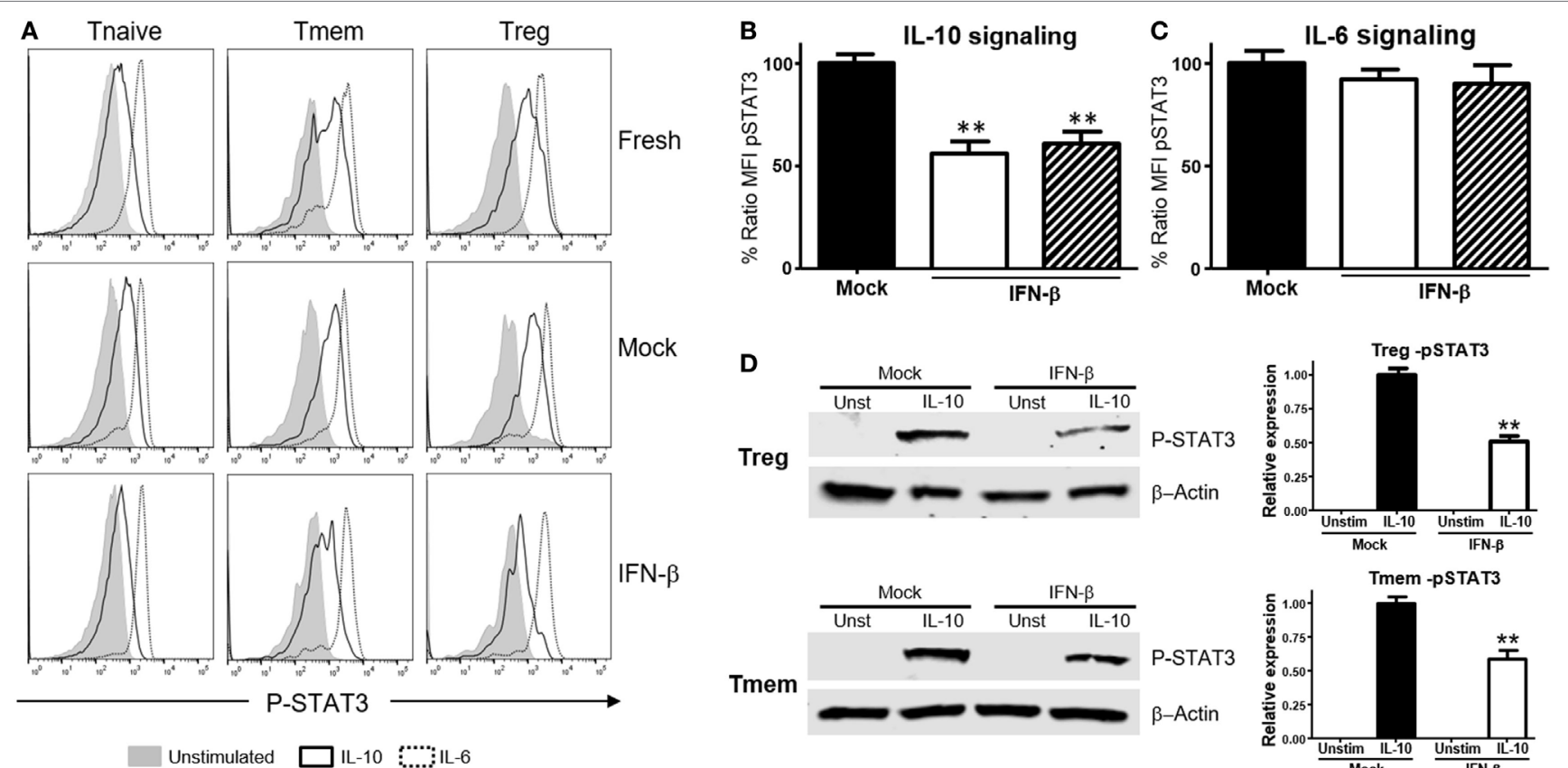

FIGURE 2 | Exposure to IFN- $\beta$ induces a selective inhibition of interleukin-10 (IL-10) signaling in CD4 memory T cells (Tmem) and regulatory T cell (Treg) irrespective of the strain of origin. (A-C) Purified T cells from C57BL/6 mice were freshly stimulated or cultured for $48 \mathrm{~h}$ in complete media with or without IFN- $\beta$ (5 ng/ml), and rested in cytokine-free media for six additional hours. Cells were then either left untreated or stimulated with IL-10 (40 ng/ml) or IL-6 (40 ng/ml) for 20 min, and the levels of P-STAT3 in CD4 T cell subpopulations were measured by Phospho-flow as in Figure 1. (A) Representative histograms of the mean fluorescence intensity (MFI) levels of P-STAT3 in the different CD4 T cell subpopulations of fresh, mock, and IFN- $\beta$ exposed T cells after IL-10 and IL-6 stimulation. (B,C) Graph bars that compare the percentage of P-STAT3 MFI ratio between IFN- $\beta$ exposed and not exposed (mock) cultured Tmem and Tregs after IL-10 (B) or IL-6 (C) stimulation. Ratio MFI was calculated comparing the coefficient index of P-STAT3 after stimulation between the two different culture conditions, considering levels in mock cells as $100 \%$ of expression. Data from $n=6$ individual experiments are shown and expressed as $\%$ of ratio MFI \pm SEM, ${ }^{\star \star} p<0.01$, Mann-Whitney $U$ test. (D) T cells from C57BL/6-Foxp3-GFP mice were cultured for $48 \mathrm{~h}$ in complete media with or without IFN- $\beta$ (5 ng/ml), and then Tmem (CD4+Foxp3-GFP-CD44+) and Treg $\left(\mathrm{CD}^{+}{ }^{+}\right.$Foxp3-GFP+) subpopulations were flow sorted. After a $6 \mathrm{~h}$ resting phase, cells were left untreated or stimulated with IL-10 (40 ng/ml) for 20 min, lysed and the levels of PSTAT3 compared to $\beta$-actin were measured by Western Blot. Data from $n=3$ individual experiments are shown and expressed as a relative expression with the control $\pm \mathrm{SEM},{ }^{\star \star} p<0.01$, Student's $t$-test.

of Tmem, we implemented the previously published "parking method" (see Materials and Methods) where in vitro-activated $\mathrm{T}$ cells are "parked" in congenic $\mathrm{Rag}^{-1-}$ mice to generate Tmem (26). Tregs were freshly isolated from unmanipulated animals. Gene transcription analysis showed four genes-LIGHT (Tnfsf14), Sphk1, Tarm1, and 2B4-to be significantly upregulated in Tmem by in vitro treatment with IL-10 (Figure 3A), and two genes, Sphk1 and 2B4, were upregulated in Treg. We then analyzed if the induction of these genes was affected by pre-exposure of these cells in vitro to IFN- $\beta$. In Tmem, the increased expression of LIGHT, Sphk1, Tarm1, and 2B4 was completely abrogated. mRNA levels of Sphk1, LIGHT, and Tarm1 also showed an important decrease in IFN- $\beta$ exposed Treg, while the expression of $2 B 4$ was not affected. Supported by these results, we determined whether the in vivo exposure of NOD T cells to normal (spleen) or high levels of TI-IFN (PLN and MLN) affected the induction of these genes by IL-10. Tmem and Tregs were flow sorted from spleen and from pooled PLN + MLN and then stimulated ex vivo with IL-10 (Figure 3B). Tmem cells from the spleen showed a significant upregulation of LIGHT, Sphk1, and Tarm1, while all four genes could not be induced by IL-10 in cells from PLN + MLN. In NOD Treg, IL-10 induced a statistical increase in LIGHT and Tarm1 in cells from the spleen while, again, none of them was upregulated in cells from PLN + MLN. These results indicate that the selective inhibition of STAT3 phosphorylation induced by INF- $\beta$ pre-exposure alters significantly the impact of IL-10-induced transcription in Tmem and Tregs both in vitro and in vivo.

\section{Inhibition of IL-10 Signaling Requires Prolonged Exposure to IFN- $\beta$, but It Is Reversible}

To explore what length of exposure to IFN- $\beta$ is required to impact IL-10 signaling in T cells, wt B6 bulk T cells were exposed to IFN- $\beta$ for different lengths of time and the response to IL-10 and IL-6 (not shown) in different subsets assessed by Phospho-flow. In Tmem cells, a 24-h exposure significantly reduced the levels of IL-10-induced P-STAT3, but a 48-h exposure was necessary to achieve maximal inhibition (Figure 4A). In Tregs, a 24-h exposure was sufficient to achieve the maximal inhibition of IL-10-induced P-STAT3 signaling (Figure 4A).

We also tested the reversibility of this inhibition. To address this question, after $48 \mathrm{~h}$ of exposure to IFN- $\beta$, T cells were washed, rested in cytokine-free media for 24 or $48 \mathrm{~h}$ and the P-STAT3 


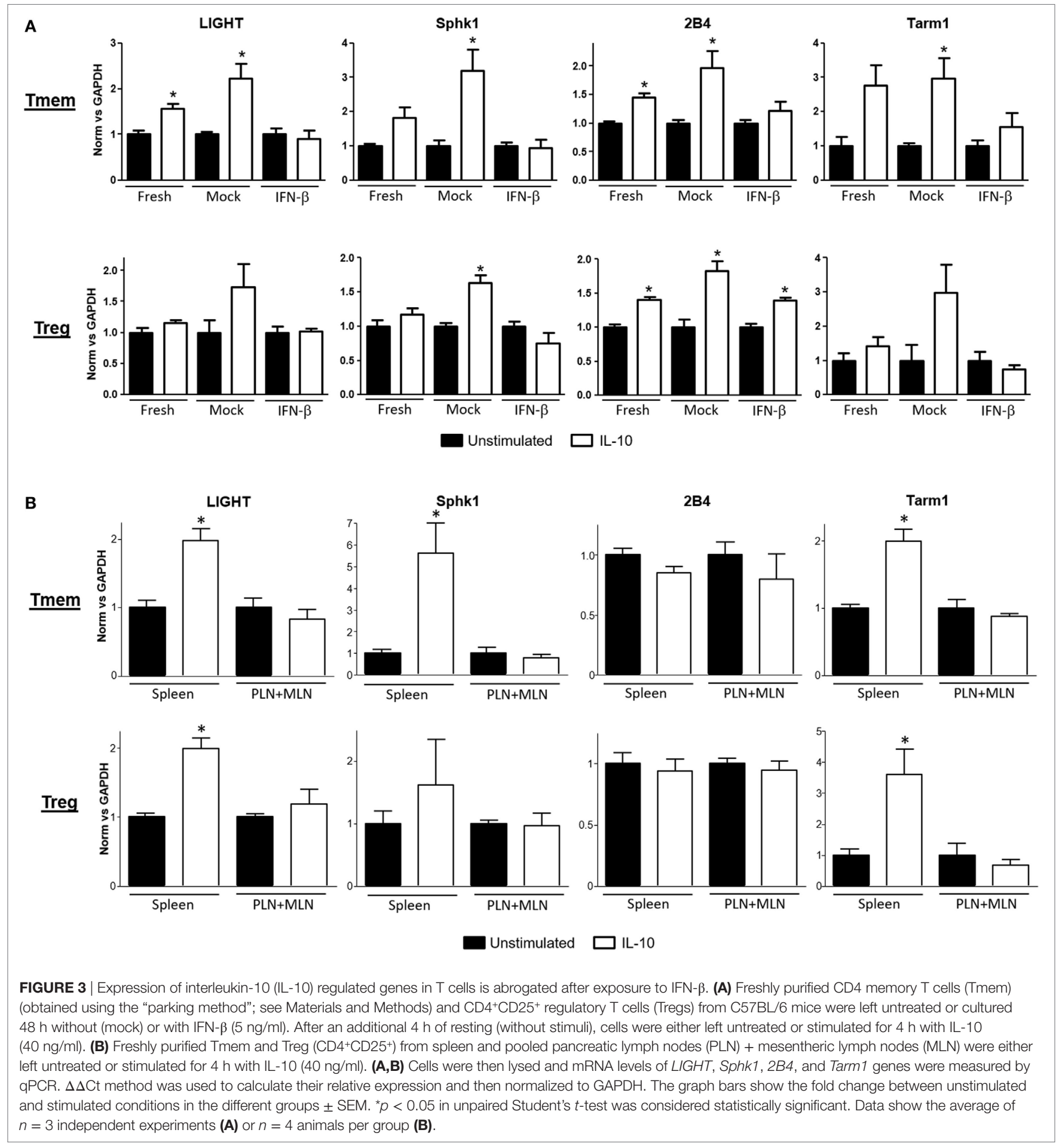

response to IL-10 or IL-6 (not shown) was then measured. Within $24 \mathrm{~h}$ of removing IFN- $\beta$, Treg recovered their normal P-STAT3 response to IL-10 (Figure 4B). The recovery of Tmem was slower, showing only partial restoration of the IL-10 signaling even at $48 \mathrm{~h}$ after removing the IFN- $\beta$ (Figure $4 \mathrm{~B}$ ). We then determined if the reversibility of inhibition applied also to NOD T cells from PLN and MLN, where they are exposed to high concentrations of a cocktail of TI-IFNs (and possibly for a long period of time). Total cells from spleen, PLN, and MLN of NOD mice were freshly isolated, rested in cytokine-free media for $48 \mathrm{~h}$, and the P-STAT3 response to IL-10 was then measured. Results showed a significant recovery in both Treg and Tmem cells from PLN and MLN rested in IFN- $\beta$ free media (Figure 4C). These results indicate that the bystander effect of IFN- $\beta$ requires a prolonged exposure 

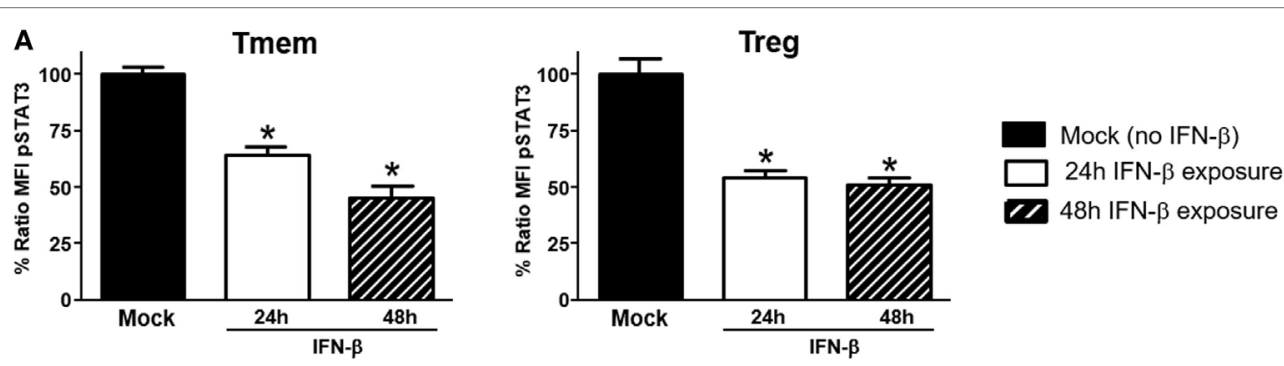

B
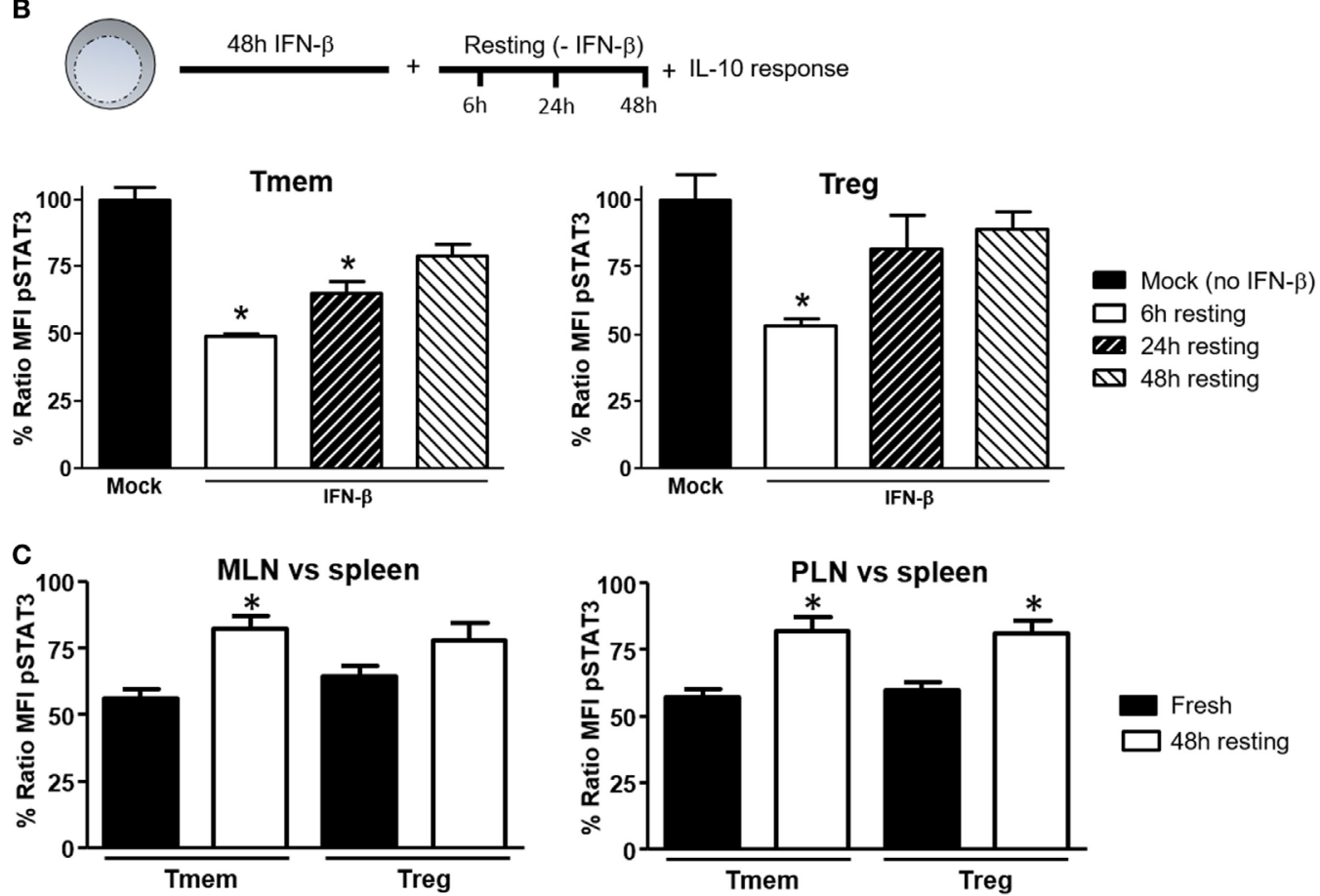

FIGURE 4 | Induction of interleukin-10 (IL-10) signaling inhibition in T cells requires prolonged exposure to IFN- $\beta$ but is reversible. (A) Purified T cells from C57BL/6 mice were cultured for 24 or $48 \mathrm{~h}$ with or without IFN- $\beta(5 \mathrm{ng} / \mathrm{ml})$ and rested in cytokine-free media for six additional hours. Cells were then left untreated or stimulated with IL-10 $(40 \mathrm{ng} / \mathrm{ml})$ and the inhibition of P-STAT3 induction by IL-10 assessed as indicated in Figure 1. (B) Purified T cells from C57BL/6 mice were cultured for $48 \mathrm{~h}$ with or without IFN- $\beta$ ( $5 \mathrm{ng} / \mathrm{ml})$ and then rested in cytokine-free media for the indicated time $(6,24$, and 48 h). The levels of P-STAT3 in response to IL-10 (40 ng/ml) were then assessed as previously indicated. The ratio mean fluorescence intensity (MFI) (A,B) was calculated comparing the coefficient index of P-STAT3 after IL-10 stimulation between IFN- $\beta$ exposed and mock, considering levels in mock cells as $100 \%$ of expression. Data of $n=4$ individual experiments are shown and expressed as \% of ratio MFI \pm SEM, ${ }^{*} p<0.05$, Mann-Whitney $U$ test. (C). Cells from pancreatic lymph nodes (PLN), mesentheric lymph nodes (MLN), and spleens of 4- to 6-week-old nonobese diabetic (NOD) mice were either freshly stimulated or cultured in cytokine-free media for $48 \mathrm{~h}$ and then stimulated with IL-10 (40 ng/ml) for $20 \mathrm{~min}$. The levels of P-STAT3 in response to IL-10 (40 ng/ml) were then assessed as previously indicated. Cumulative results are shown in the graph where bars represent the normalized P-STAT3 MFI ratio in memory T cells (Tmem) or regulatory T cell (Treg) after IL-10 stimulation between the spleen and PLN or MLN in fresh vs rested conditions. Ratio MFI was calculated by comparing the coefficient index of P-STAT3 between the two different organs, considering the levels in spleen as $100 \%$ of expression. Data of $n=4$ mice per group are shown and expressed as $\%$ of ratio MFI \pm SEM, ${ }^{*} p<0.05$, Mann-Whitney $U$ test.

to instigate inhibition of IL-10 signaling and, with some kinetic differences between Treg and Tmem, a normal P-STAT3 response to IL-10 in T cells can be restored following removal of IFN- $\beta$.

\section{IFN- $\beta$ Signals Through the Jak/STAT Pathway to Inhibit IL-10 Signaling in T Cells}

Type-I interferons signal through multiple pathways (30), with the activation of the Jak/STAT route considered the most relevant to their antiviral effects. To identify the signaling pathway responsible for the actuation of IFN- $\beta$-induced perturbations of IL-10 signaling, cells were pre-treated with two small molecule Jak-specific inhibitors, Tofacitinib and Ruxolitinib, prior to and during IFN- $\beta$ stimulation. Tofacitinib inhibits Jak3 and Jak1, while Ruxolitinib blocks Jak2 and Jak1. After preconditioning bulk T cells with Tofacitinib $(25 \mu \mathrm{M})$ or Ruxolitinib $(5 \mu \mathrm{M})$ for $2 \mathrm{~h}$, IFN- $\beta$ was added to the cultures for $48 \mathrm{~h}$. Following incubation and washing, an additional $6-8 \mathrm{~h}$ resting phase allowed the cells to recover their signaling after removal of the Jak inhibitor (Figure S4 in Supplementary Material). The impact on IL-10 or IL-6 signaling was then quantified via phospho-flow. In Tmem, 
Tofacitinib treatment resulted in a statistically significant preservation of IL-10 signaling and Ruxolitinib had an even stronger effect (Figure 5A). In Treg, both inhibitors restored IL-10 signaling to the same extent (Figure 5A), though the cells had to be rested for $8 \mathrm{~h}$ (instead of $6 \mathrm{~h}$ as in the case of Tmem), as their recovery of cytokines signaling after Jak inhibition was slower than in Tmem. Collectively, these results suggest that Jak1, and possibly Jak2, are essential mediators for IFN- $\beta$-mediated alterations of IL-10-induced P-STAT3 signaling in T cells.

Our data indicate that TI-IFN causes inhibition of IL-10 signaling through a process that requires $24 / 48 \mathrm{~h}$ of exposure. This suggests that multiple intracellular molecular modifications are needed to achieve this phenotype and the process could require the synthesis and activity of additional extracellular mediators. To test this hypothesis, we employed a co-culture system with T cells deficient for the receptor of TI-IFN (IFN-AR1 ${ }^{-/}$; unable to respond to IFN- $\alpha$ or $-\beta$ ). These cells have a response to IL-10 comparable to that displayed by wild type cells (Figure S5 in Supplementary Material). We then exposed B6 wild-type congenic T cells (CD45.1 $1^{+}$ from B6/SJL mice) mixed at 1:1 ratio with B6-IFN-AR1 ${ }^{-1-} \mathrm{T}$ cells (expressing the CD45.2 isoform) to IFN- $\beta$. If the TI-IFN-induced inhibition of IL-10 signaling requires the synthesis and secretion of an intermediate factor, this molecule would also affect the response of IFN-AR1 $1^{-1-} \mathrm{T}$ cells in our co-culture system (Figure 5B). Phospho-flow analysis indicated that while wild-type Tmem and Tregs showed a reduction of IL-10 signaling after IFN- $\beta$ exposure, the co-cultured IFN-AR1 $1^{-/}$cells remained completely unaffected (Figure 5C). These results demonstrate that IFN- $\beta$ acts directly on T cells to condition IL-10 signaling.

\section{Alteration of Surface IL-10 Receptor Expression or Induction of SOCS Molecules Are Not Responsible For Inhibition of IL-10 Signaling}

Downregulation of IL-10R surface expression would be a plausible mechanism to account for the inhibition of IL-10 signaling following exposure to TI-IFN. However, flow cytometric analysis of IL-10R surface expression did not support this hypothesis. IFN- $\beta$ exposed $\mathrm{T}$ cells (both Tmem and Treg), expressed levels of the receptor comparable to that of non-exposed cells (Figure 6A). In line with this, the comparison of IL-10R expression between NOD T cells isolated from the PLN, MLN, ALN, and spleen showed no differences in the MFI (Figure 6B). This result suggested the involvement of an IL-10R-specific regulator acting between the receptor and STAT3 (as STAT3 remains available for the IL-6 receptor to be phosphorylated). SOCSs act as cytokineinducible negative regulators of cytokine signaling. We tested if the transcriptional levels of SOCS1 (the only regulator reported in the literature to be associated with inhibition of IL-10 signaling in a lymphoma cell line) (31) and SOCS3 (as control; it does not inhibit IL-10R) were increased by IFN- $\beta$ treatment. Despite a reduction in the SOCS1 and SOCS3 RNA levels in cultured $\mathrm{T}$ cells compared to fresh cells, the transcription levels of SOCS1 and SOCS3 were not increased by IFN- $\beta$ treatment (Figure 6C). These results were confirmed in Tmem and Treg subpopulations via Prime FlowRNA (Affymetrix)-technology that allows detection via flow cytometry of RNA and protein expression simultaneously at single cell level-clearly showing that the levels
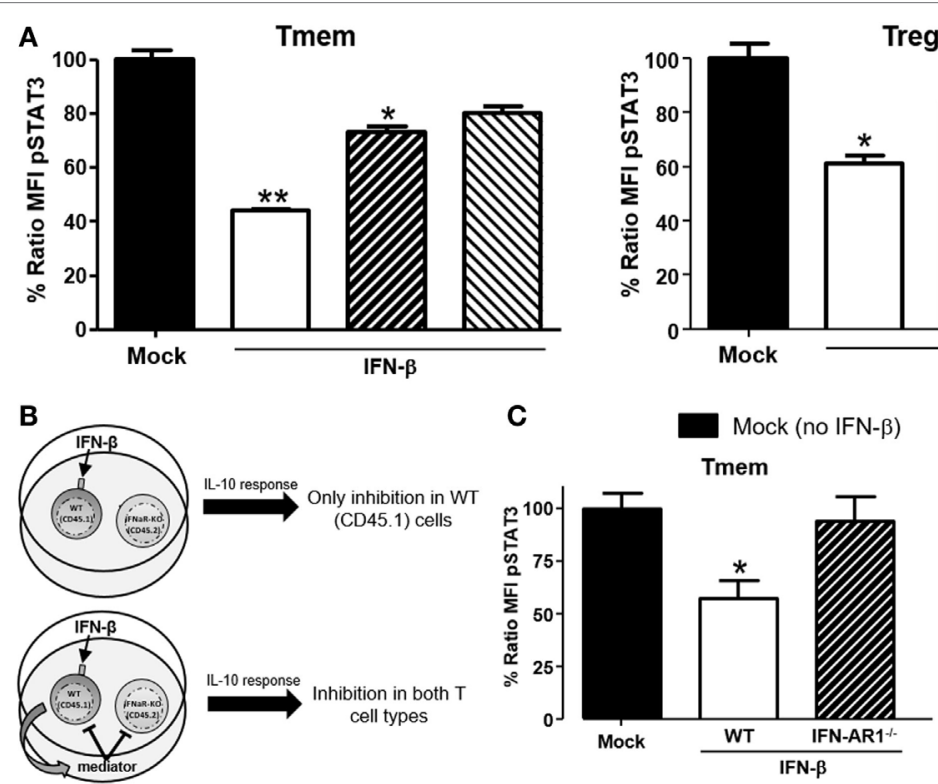

Treg
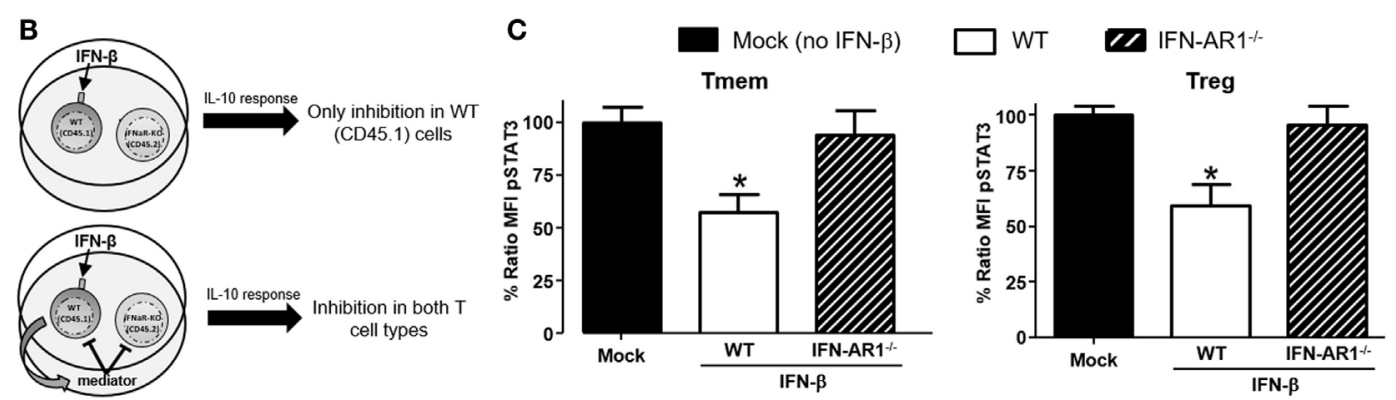

FIGURE 5 | IFN- $\beta$ signals through JAK-STAT pathway to directly inhibit interleukin-10 (IL-10) signaling in T cells. (A) Impact of JAK-STAT inhibition on the ability of IFN- $\beta$ to modulate IL-10 signaling. T cells from C57BL/6 mice were exposed to Tofacitinib ( $25 \mu \mathrm{M})$ or Ruxolitinib $(5 \mu \mathrm{M})$ for $2 \mathrm{~h}$ before addition of IFN- $\beta$ and then cultured for $48 \mathrm{~h}$ (followed by a $6-8 \mathrm{~h}$ resting phase in cytokine-free media). Their ability to respond to IL-10 (40 ng/ml) was then measured by means of P-STAT3 levels assessed via Phospho-flow. (B) Schematic representation of the experimental approach adopted to assess the direct or indirect impact of IFN- $\beta$. (C) Purified T cells from congenic C57BL/6 (CD45.1) and IFN-AR1-/- (CD45.2) mice were mixed at a 1:1 ratio. This mix was cultured for $48 \mathrm{~h}$ with or without IFN- $\beta$ (5 $\mathrm{ng} / \mathrm{ml})$ and then rested in cytokine-free media for additional $6 \mathrm{~h}$. The response to IL-10 of each subpopulation was then assessed via Phospho-flow. Data of $n=3$ individual experiments are shown and expressed as \% of ratio mean fluorescence intensity (MFI) \pm SEM, ${ }^{*} p<0.05,{ }^{* *} p \leq 0.01$, paired Student's $t$-test. 


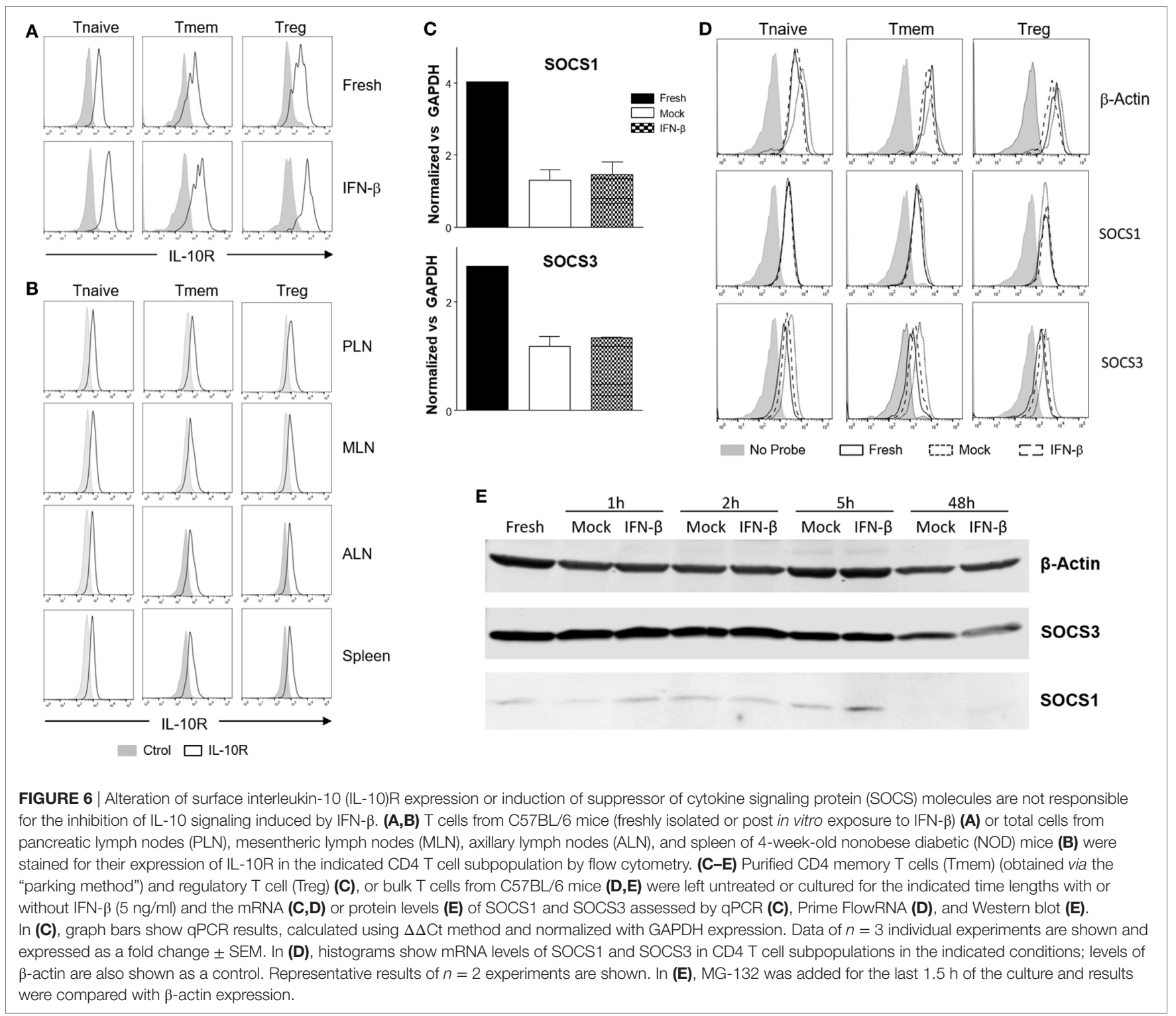

of SOCS1 and SOCS3 RNA were not upregulated in Tmem and Tregs exposed to IFN- $\beta$ (Figure 6D). Finally, we assessed the level of SOCS1 and SOCS3 protein via western blot at both early time point after addition of IFN- $\beta$ as well as at the investigated $48 \mathrm{~h}$ (Figure 6E). Results indicate that despite IFN- $\beta$ induces a modest increase in SOCS1 levels in the first few hours of stimulation, such increase is not sustained at $48 \mathrm{~h}$ and excludes the involvement of SOCS1 in IL-10 signaling inhibition.

\section{The Localized Defective Response to IL-10 in Tmem and Tregs of NOD Mice Is Maintained With Age}

Knowing whether the inhibition of IL-10 signaling in T cells of PLN and MLN of NOD mice is sustained or altered over time is important for defining possible windows of therapeutic intervention. The accumulation of TI-IFN in PLN (13) appears maintained over time, though to a progressively lower level. As the inhibition of IL-10 signaling correlates with TI-IFN levels, we executed a longitudinal analysis of the response to IL-10 and IL- 6 by Treg and Tmem cells of female NOD mice of different ages (weeks: 2, 3, 4, 6, 12, and 18). An identical analysis was performed in age-matched female wt B6 mice. Throughout the observation period, the ratio of IL-10 induced P-STAT3 in T cells between PLN/spleen and MLN/spleen (as shown in Figure 1) was significantly lower than that exhibited by B6 mice (Figure 7A). Interestingly, in 2-week-old B6 mice, the response to IL-10 of Tmem and Tregs in PLN and MLN was slightly lower than that observed in the spleen $(<100 \%)$, but it quickly recovered and stabilized (Figure 7A). 
A

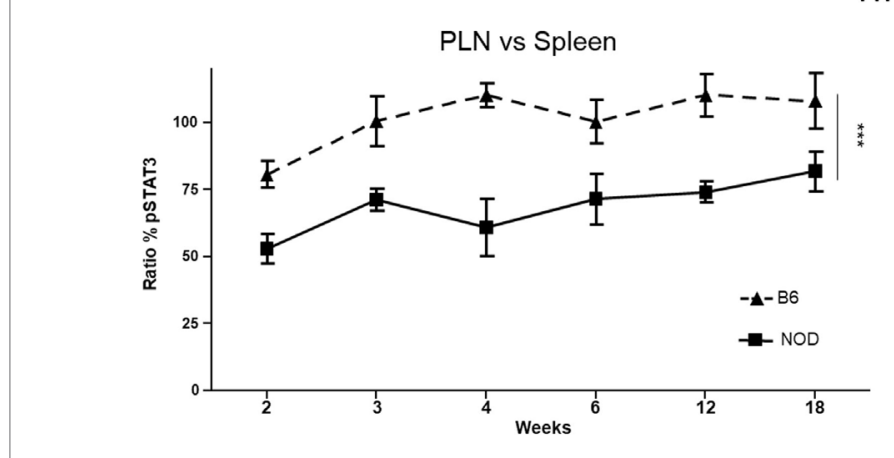

Tmem
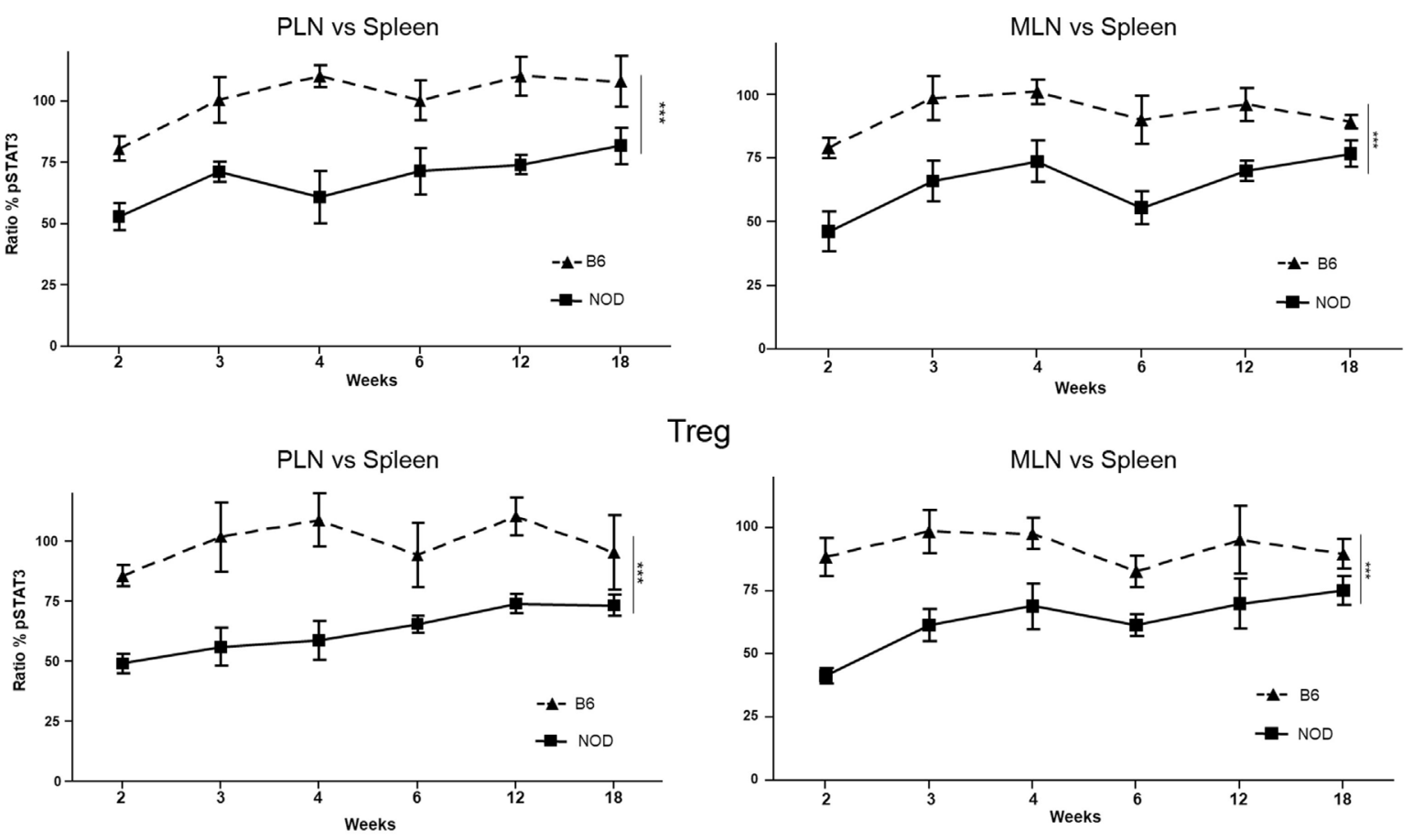

Treg

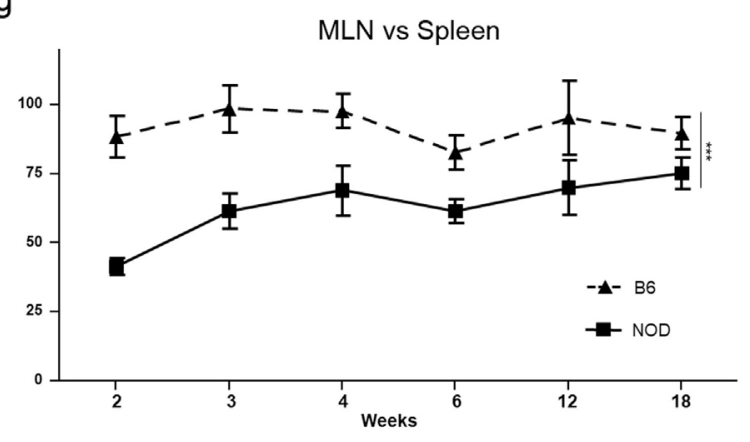

B

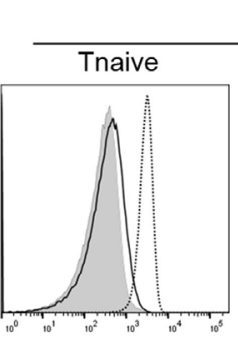

MLN
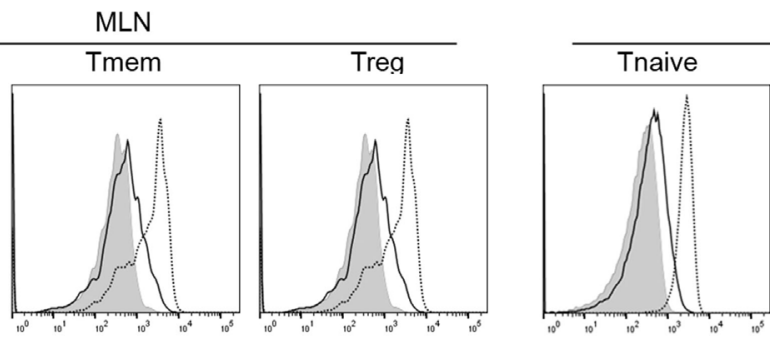

PLN
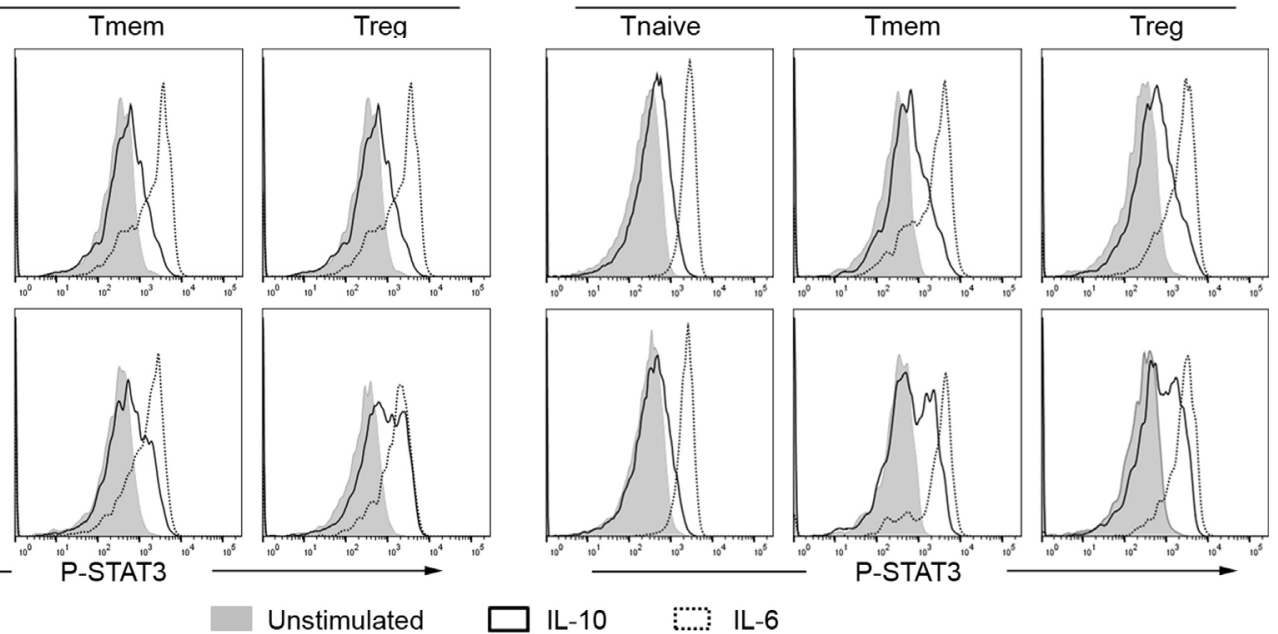

C
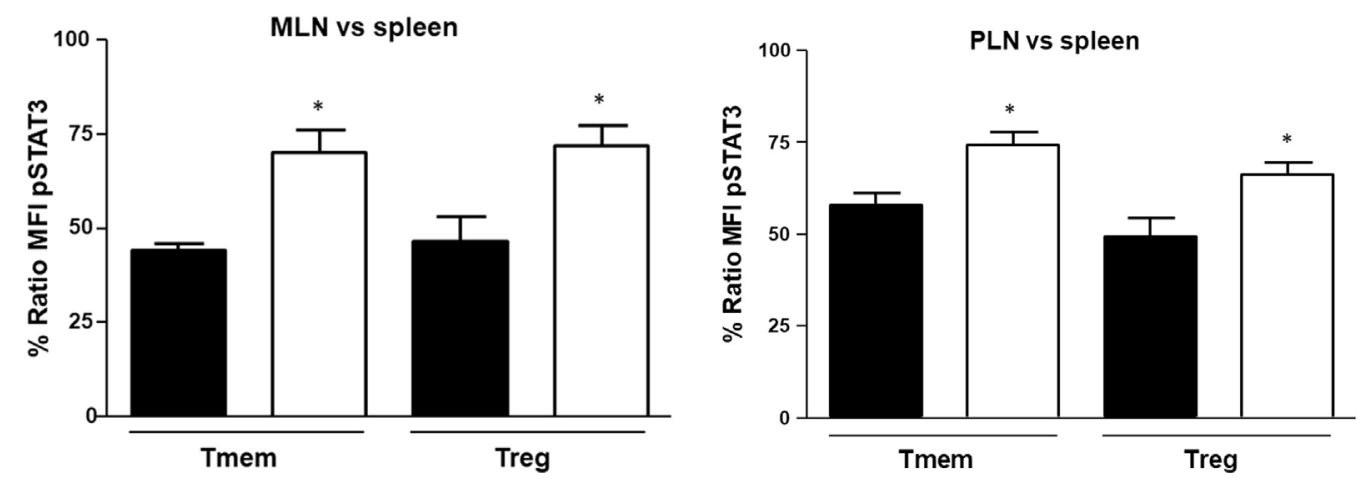

Ctrl

$\square$-IFN-AR1

FIGURE 7 | Continued 
FIGURE 7 | The localized inhibition of interleukin-10 (IL-10) signaling in T cells is sustained throughout the life of nonobese diabetic (NOD) mice and depends on IFN- $\beta$ signaling. (A) P-STAT3 induction in response to IL-10 in T cell subsets of pancreatic lymph nodes (PLN), mesentheric lymph nodes (MLN), and spleen collected from NOD and C57BL/6 mice at the indicated age. Graph indicate the kinetic of P-STAT3 mean fluorescence intensity (MFI) ratio between the spleen and PLN or MLN (as indicated) memory T cells (Tmem) and regulatory T cell (Treg) after IL-10 stimulation. Final value was calculated by comparing the coefficient index of P-STAT3 between the two different organs, considering the levels in spleen as $100 \%$ of expression. Data of $n=4$ mice per strain and per age point are shown and expressed as \% of ratio MFI \pm SEM. Differences between B6 and NOD were calculated using a two-way ANOVA (** $p<0.001$ ). (B,C) Transient blockade of type-I interferons (TI-IFNs) signaling partially restores IL-10 signaling in T cells. NOD mice were treated with control or a blocking anti-IFNA-R mAb (0.5 mg on days 14 and 21 of age) and, on day 25, PLN, MLN, and spleen were extracted. Cells were left untreated or stimulated with IL-10 (40 ng/ml) or IL-6 (40 ng/ml) and the levels of P-STAT3 in CD4 T cell subpopulations measured via Phospho-flow. Representative histograms are presented in (B). Cumulative results are shown in (C), where graph bars represent the normalized P-STAT3 MFI ratio in Tmem or Treg after IL-10 stimulation between the spleen and PLN or MLN in control vs treated NOD mice. Ratio MFI was calculated by comparing the coefficient index of P-STAT3 between the two different organs, considering the levels in spleen as $100 \%$ of expression. Data of $n=4$ mice per treatment group are shown and expressed as \% of ratio MFI \pm SEM, ${ }^{\star} p<0.05$, Mann-Whitney $U$ test.

\section{The Early Blockade of TI-IFN Signaling Partially Restores the Response to IL-10 in PLN and MLN Tmem and Tregs in NOD Mice}

The reported delay and lower incidence of diabetes development in NOD mice treated at 2-3 weeks of age with an anti-IFN-AR1 $\mathrm{mAb}(13)$, together with the reversibility of IL-10 signaling inhibition we observed in vitro in T cells after removing IFN- $\beta$, are encouraging indications that the unbalanced immune regulation of NOD mice can be prevented or restored. To test if the therapeutic blockade of TI-IFN and alteration of IL-10 signaling were correlated in vivo in NOD mice, anti-IFN-AR1 mAb was administered on days 14 and 21 of age in female NOD mice and, on day 25, we measured the induction of P-STAT3 in PLN and MLN $\mathrm{T}$ cell subsets in response to ex vivo IL-10 treatment. Both Tmem and Treg populations in PLN and MLN of anti-IFN-AR-treated animals showed a significant recovery in P-STAT3 induction in response to IL-10 (Figures 7B,C). These results suggest that the therapeutic effect of early administration of anti-IFN-AR1 mAb in NOD mice may be due to the restoration of IL-10 signaling.

\section{DISCUSSION}

In addition to genetic susceptibility, type 1 diabetes development is clearly linked to still poorly defined environmental factors contributing to the initiation and/or progression of the disease. There is a growing number of reports that associate high levels of TI-IFN with the onset and progression of this pathology (8-10, 12-14). However, mechanistic insights on how TI-IFN would favor type 1 diabetes development are lacking, contributing to a degree of confusion in understanding this connection. In particular, how the accumulation of TI-IFN could result in a localized effect that enables the activity of diabetogenic $\mathrm{T}$ cells remains an enigma. The finding that dendritic cells of NOD mice produce higher levels of TI-IFN in response to TLR stimulation than cells of B6 mice (32) provides an important clue to the causes of localized and chronic TI-IFN accumulation in PLN reported previously (13). Based on our results, we propose that this chronic accumulation of TI-IFN in NOD mice, which we report for the first time also extends to the MLN, re-programs the response of CD4 Treg and Tmem to IL-10 and potentially diminishes the homeostatic regulation of diabetogenic cells. This phenomenon likely contributes to the progressive attack to the islets and development of the disease. These data are supported by the recovery of IL-10 signaling we observed after blockade of TI-IFN-IFNR1 interactions, a treatment that results in a reduction of the disease incidence and progression in NOD mice (13).

Our results provide some important clues on the molecular mechanism behind the inhibition of IL-10 signaling. The normal level of phosphorylation of STAT3 we measured in response to IL- 6 in T cells pre-exposed to IFN- $\beta$ suggested that the impairment observed in IL-10 signaling is not caused by a generalized reduction in the cytoplasmic availability of STAT3. The lack of upregulation of SOCS1 and SOCS3 (at either the MRNA or protein level) and the unaltered (if not slightly increased) expression of IL-10R in T cells we observed post-IFN- $\beta$ exposure both in vitro and in vivo do not support regulation of P-STAT3 induction at this level. Our results suggest then that an IL-10 signaling negative regulator acting between the receptor and STAT3 phosphorylation is either being upregulated or activated. For example, direct or indirect alterations in the binding and phosphorylation of Jak1 and Tyk2 would regulate STAT3 activation (33); the involvement of molecules that interact with STAT3, including other members of the STAT family, should also be explored as they could interfere with its binding to IL-10R and its phosphorylation (30). Interestingly, human monocytes and macrophages primed with IFN $\alpha / \beta$ showed an increase in IL-10R1 and an increase in IL-10 signaling (34). However, these experiments were performed with an acute exposure $(5 \mathrm{~h})$ to TI-IFN. A prolonged exposure of human macrophages to TI-IFN promoted a switch in the signaling of IL-10 from activation of STAT3 to STAT1 $(35,36)$; in our settings, however, STAT1 phosphorylation was not appreciable in any condition tested (not shown). Overall, these observations suggest that IFN- $\beta$ can have different consequences depending on the timing and context of exposure as well as on the target cell population, probably contributing to the (sometimes discordant) range of outcomes attributed to TI-IFN (37). Our ongoing work is now focused on dissecting these regulatory mechanisms and identify previously unappreciated modulators of IL-10 signaling.

The protective effect of Tofacitinib and Ruxolitinib we observed in our experiments indicates that signaling through the Jak/STAT pathway is involved in this specific effect of TI-IFNthough we cannot exclude the participation of other signaling routes (38). A deeper understanding of the molecular mediators of this phenomenon would be of crucial importance as some of these molecules could be targeted to control the development of diabetes. In fact, Jak1/Jak2 inhibition in vivo is effective at 
preventing, and reverting, established insulitis in NOD mice $(39,40)$. Improving the efficacy and safety of this type of intervention would be a major advancement for type 1 diabetes patients.

Our study shows that Tmem and Treg with impaired IL-10 signaling are present not only in PLN but also in the regionally close MLN. Paralleling the results from Rahman and colleagues (32), this phenomenon is specific for NOD animals, as in B6 mice, the response to IL-10 was not affected. This strain-specific effect in lymph nodes draining the gut (41) suggests a link with the recently discovered role of the microbiota in autoimmune diabetes development $(2,4)$; it could indicate an aberrant heightened chronic response to specific bacterial (or viral) derivatives that is not properly regulated. The initial impairment in IL-10 signaling we observed in 2-week-old B6 pups (similar to, but not to the same extent as, that of NOD mice, Figure 7), could indicate an initial adaptation phase of the newly generated pool of T cells (exposed to TI-IFN in the thymus) (42) to variations in the intestinal flora during the breast-feeding phase. This would suggest that the genetic predisposition of NOD mice encompasses a defect in establishing the proper balance in the response to microbiota derivatives in the gut-draining lymph nodes that ultimately affects the regulation of diabetogenic T cells by IL- 10 .

We observed that the impact of TI-IFN is not specific to the NOD genetic background, suggesting that this novel mechanism of alteration of immunoregulation could also contribute to the development of other disorders with a TI-IFN signature (43). This is a significant finding as the reduction of IL-10 signaling in Treg and Tmem populations has very deleterious effects on regulating autoreactivity (23-25). In animal models of diabetes $(44,45)$ as well as diabetic patients (46), Tregs exhibit reduced regulatory efficacy while effector $\mathrm{T}$ cells are resistant to regulation (44). Altogether, these results point toward a loss of regulation of autoreactive $\mathrm{T}$ lymphocytes as a key process in diabetes development. A selective targeting of this phenomenon, by either correcting the aberrant production of TI-IFN or by preventing its modulation of IL-10 signaling, could significantly improve the efficacy of some approaches currently being explored for the treatment of type 1 diabetes (47). Targeting IL-10 signaling has already been considered in the treatment of this disease $(16,17)$. However, inconsistent effects have been reported (48-51). Based on our results, we suggest that, rather than augmenting the concentration of IL-10, a targeted restoration of the IL-10 impact on diabetogenic cells ( $v i a$ a timed and localized intervention) would achieve more successful therapeutic outcomes. To this end, understanding how IL-10 modulates T cell function is necessary to identify the best strategy to recover an appropriate level of regulation but, to date, very little is known. We report here for the first time several genes (Sphk1, LIGHT, Tarm1, and 2B4) that IL-10 induces in T cells. We used their expression as readout of IL-10 function, demonstrating the impact of pre-exposure to TI-IFN both in vitro and in vivo in NOD mice. Our future studies will be centered on understanding the transcriptional impact of IL-10 on $\mathrm{T}$ cells and the involvement of specific genes in the modulation of $\mathrm{T}$ cell functions. Moreover, the differential expression profile of the four genes between Tmem and Treg populations suggests a distinct role in each population; a property that could also reveal strategies to selectively impact these two subsets.
In summary, our study unveils the existence of a new molecular mechanism through which TI-IFN can alter T cell regulation and improves our understanding of IL-10-mediated control of Treg and Tmem cells. A deeper understanding of this phenomenon will very likely reveal novel points of intervention to restore the necessary immune regulatory network to potentiate the efficacy of immunotherapies for type 1 diabetes and possibly other autoimmune diseases.

\section{ETHICS STATEMENT}

All animal experiments were conducted in accordance with the National Institutes of Health guide for use and care of laboratory animals, and under a protocol approved by the JHU Animal Care and Use Committee.

\section{AUTHOR CONTRIBUTIONS}

MI and GR developed the project, researched data, designed experiments, and wrote the manuscript. AA, MC, and BL contributed to experimental design and researched data. CT and VI researched data. WL and GB contributed to data interpretation, troubleshooting, and provided essential manuscript feedback. GR is the guarantor of this work and, as such, had full access to all the data in the study and takes responsibility for the integrity of the data and the accuracy of the data analysis.

\section{ACKNOWLEDGMENTS}

The authors thank Sonia Santiago (laboratory manager), and Xiaoling Zhang (flow cytometry specialist), both at Johns Hopkins University, for excellent technical assistance; Dawn Hull and Kamal Abdi (animal facility supervisors; Johns Hopkins University) for animal husbandry and care; and Dr. Mark Donowitz (for granting access to his Odyssey CLx LI-COR). We would also like to thank Dr. Ranjeny Thomas (University of Queensland, Australia), Dr. John Alcorn (University of Pittsburgh), Drs. Alan Scott, Thomas Donner, Edward Harhaj, Erika Darrah, Tory Johnson (Johns Hopkins University), Dr. Francesca Granucci (University of Milano-Bicocca, Italy), and Dr. Ivan Zanoni (Harvard University) for invaluable feedback on experimental design, troubleshooting, and manuscript preparation.

\section{FUNDING}

This work was supported by American Diabetes Association Junior Faculty Award 1-10-JF-43, a Starzl Transplantation Institute Joseph Patrick Fellowship, a Pilot and Feasibility Grant from the Baltimore Diabetes Research Center, an American Association of Immunologists 2016-2017 Careers in Immunology Fellowship, and JDRF strategic research agreement 2-SRA-2016-304-S-B (all to GR).

\section{SUPPLEMENTARY MATERIAL}

The Supplementary Material for this article can be found online at https:/www.frontiersin.org/articles/10.3389/fimmu.2018.01565/ full\#supplementary-material. 


\section{REFERENCES}

1. Castano L, Eisenbarth GS. Type-I diabetes: a chronic autoimmune disease of human, mouse, and rat. Annu Rev Immunol (1990) 8:647-79. doi:10.1146/ annurev.iy.08.040190.003243

2. Li X, Atkinson MA. The role for gut permeability in the pathogenesis of type 1 diabetes - a solid or leaky concept? Pediatr Diabetes (2015) 16:485-92. doi:10.1111/pedi.12305

3. Petzold A, Solimena M, Knoch KP. Mechanisms of beta cell dysfunction associated with viral infection. Curr Diab Rep (2015) 15:73. doi:10.1007/ s11892-015-0654-x

4. Scott FW, Pound LD, Patrick C, Eberhard CE, Crookshank JA. Where genes meet environment-integrating the role of gut luminal contents, immunity and pancreas in type 1 diabetes. Transl Res (2017) 179:183-98. doi:10.1016/j. trsl.2016.09.001

5. Shizuru JA, Taylor-Edwards C, Banks BA, Gregory AK, Fathman CG. Immunotherapy of the nonobese diabetic mouse: treatment with an antibody to T-helper lymphocytes. Science (1988) 240:659-62. doi:10.1126/science. 2966437

6. Thivolet C, Bendelac A, Bedossa P, Bach JF, Carnaud C. CD8+ T cell homing to the pancreas in the nonobese diabetic mouse is CD4+ T cell-dependent. J Immunol (1991) 146:85-8.

7. Christianson SW, Shultz LD, Leiter EH. Adoptive transfer of diabetes into immunodeficient NOD-scid/scid mice. Relative contributions of CD4+ and CD8+ T-cells from diabetic versus prediabetic NOD.NON-Thy-1a donors. Diabetes (1993) 42:44-55. doi:10.2337/diab.42.1.44

8. Niewold TB. Type I interferon in human autoimmunity. Front Immunol (2014) 5:306. doi:10.3389/fimmu.2014.00306

9. Huang X, Yuang J, Goddard A, Foulis A, James RF, Lernmark A, et al. Interferon expression in the pancreases of patients with type I diabetes. Diabetes (1995) 44:658-64. doi:10.2337/diabetes.44.6.658

10. Meyer S, Woodward M, Hertel C, Vlaicu P, Haque Y, Karner J, et al. AIREdeficient patients harbor unique high-affinity disease-ameliorating autoantibodies. Cell (2016) 166:582-95. doi:10.1016/j.cell.2016.06.024

11. Stewart TA, Hultgren B, Huang X, Pitts-Meek S, Hully J, Maclachlan NJ. Induction of type I diabetes by interferon-alpha in transgenic mice. Science (1993) 260:1942-6. doi:10.1126/science.8100367

12. Pearson JA, Wong FS, Wen L. The importance of the Non Obese Diabetic (NOD) mouse model in autoimmune diabetes. J Autoimmun (2016) 66: 76-88. doi:10.1016/j.jaut.2015.08.019

13. Li Q, Xu B, Michie SA, Rubins KH, Schreriber RD, Mcdevitt HO. Interferonalpha initiates type 1 diabetes in nonobese diabetic mice. Proc Natl Acad Sci US A (2008) 105:12439-44. doi:10.1073/pnas.0806439105

14. Ferreira RC, Guo H, Coulson RM, Smyth DJ, Pekalski ML, Burren OS, et al. A type I interferon transcriptional signature precedes autoimmunity in children genetically at risk for type 1 diabetes. Diabetes (2014) 63:2538-50. doi:10.2337/db13-1777

15. Sabat R, Grutz G, Warszawska K, Kirsch S, Witte E, Wolk K, et al. Biology of interleukin-10. Cytokine Growth Factor Rev (2010) 21:331-44. doi:10.1016/j. cytogfr.2010.09.002

16. Teros T, Hakala R, Ylinen L, Liukas A, Arvilommi P, Sainio-Pollanen S, et al. Cytokine balance and lipid antigen presentation in the NOD mouse pancreas during development of insulitis. Pancreas (2000) 20:191-6. doi:10.1097/00006676-200003000-00013

17. Kaas A, Pfleger C, Kharagjitsingh AV, Schloot NC, Hansen L, Buschard K, et al. Association between age, IL-10, IFNgamma, stimulated C-peptide and disease progression in children with newly diagnosed Type 1 diabetes. Diabet Med (2012) 29:734-41. doi:10.1111/j.1464-5491.2011.03544.x

18. Ip WKE, Hoshi N, Shouval DS, Snapper S, Medzhitov R. Anti-inflammatory effect of IL-10 mediated by metabolic reprogramming of macrophages. Science (2017) 356:513-9. doi:10.1126/science.aal3535

19. de Waal Malefyt R, Yssel H, De Vries JE. Direct effects of IL-10 on subsets of human CD4+ T cell clones and resting T cells. Specific inhibition of IL-2 production and proliferation. J Immunol (1993) 150:4754-65.

20. Joss A, Akdis M, Faith A, Blaser K, Akdis CA. IL-10 directly acts on T cells by specifically altering the CD28 co-stimulation pathway. Eur J Immunol (2000) 30:1683-90.doi:10.1002/1521-4141(200006)30:6<1683::AID-IMMU1683>3. $0 . \mathrm{CO} ; 2-\mathrm{A}$
21. Naundorf S, Schroder M, Hoflich C, Suman N, Volk HD, Grutz G. IL-10 interferes directly with TCR-induced IFN-gamma but not IL-17 production in memory T cells. Eur JImmunol (2009) 39:1066-77. doi:10.1002/eji. 200838773

22. Huber S, Gagliani N, Esplugues E, O'connor W Jr, Huber FJ, Chaudhry A, et al. Th17 cells express interleukin-10 receptor and are controlled by Foxp3(-) and Foxp3+ regulatory CD4+ T cells in an interleukin-10-dependent manner. Immunity (2011) 34:554-65. doi:10.1016/j.immuni.2011.01.020

23. Kamanaka M, Huber S, Zenewicz LA, Gagliani N, Rathinam C, O'connor W Jr, et al. Memory/effector $(\mathrm{CD} 45 \mathrm{RB}(\mathrm{lo})) \mathrm{CD} 4 \mathrm{~T}$ cells are controlled directly by IL-10 and cause IL-22-dependent intestinal pathology. J Exp Med (2011) 208:1027-40. doi:10.1084/jem.20102149

24. Murai M, Turovskaya O, Kim G, Madan R, Karp CL, Cheroutre H, et al. Interleukin 10 acts on regulatory $\mathrm{T}$ cells to maintain expression of the transcription factor Foxp3 and suppressive function in mice with colitis. Nat Immunol (2009) 10:1178-84. doi:10.1038/ni.1791

25. Chaudhry A, Samstein RM, Treuting P, Liang Y, Pils MC, Heinrich JM, et al. Interleukin-10 signaling in regulatory $\mathrm{T}$ cells is required for suppression of Th17 cell-mediated inflammation. Immunity (2011) 34:566-78. doi:10.1016/j. immuni.2011.03.018

26. Lai W, Yu M, Huang MN, Okoye F, Keegan AD, Farber DL. Transcriptional control of rapid recall by memory CD4 T cells. J Immunol (2011) 187:133-40. doi:10.4049/jimmunol.1002742

27. Raimondi G, Sumpter TL, Matta BM, Pillai M, Corbitt N, Vodovotz Y, et al. Mammalian target of rapamycin inhibition and alloantigen-specific regulatory $\mathrm{T}$ cells synergize to promote long-term graft survival in immunocompetent recipients. J Immunol (2010) 184:624-36. doi:10.4049/jimmunol.0900936

28. Krutzik PO, Trejo A, Schulz KR, Nolan GP. Phospho flow cytometry methods for the analysis of kinase signaling in cell lines and primary human blood samples. Methods Mol Biol (2011) 699:179-202. doi:10.1007/978-161737-950-5_9

29. Pike KA, Hutchins AP, Vinette V, Theberge JF, Sabbagh L, Tremblay ML, et al. Protein tyrosine phosphatase $1 \mathrm{~B}$ is a regulator of the interleukin-10-induced transcriptional program in macrophages. Sci Signal (2014) 7:ra43. doi:10.1126/ scisignal.2005020

30. Ivashkiv LB, Donlin LT. Regulation of type I interferon responses. Nat Rev Immunol (2014) 14:36-49. doi:10.1038/nri3581

31. Ding Y, Chen D, Tarcsafalvi A, Su R, Qin L, Bromberg JS. Suppressor of cytokine signaling 1 inhibits IL-10-mediated immune responses. J Immunol (2003) 170:1383-91. doi:10.4049/jimmunol.170.3.1383

32. Rahman MJ, Rahir G, Dong MB, Zhao Y, Rodrigues KB, Hotta-Iwamura C, et al. Despite increased Type 1 IFN, autoimmune nonobese diabetic mice display impaired dendritic cell response to CpG and decreased nuclear localization of IFN-activated STAT1. J Immunol (2016) 196:2031-40. doi:10.4049/ jimmunol.1501239

33. Weber-Nordt RM, Riley JK, Greenlund AC, Moore KW, Darnell JE, Schreiber RD. Stat3 recruitment by two distinct ligand-induced, tyrosinephosphorylated docking sites in the interleukin-10 receptor intracellular domain. J Biol Chem (1996) 271:27954-61. doi:10.1074/jbc.271.44.27954

34. Liu BS, Janssen HL, Boonstra A. Type I and III interferons enhance IL-10R expression on human monocytes and macrophages, resulting in IL-10-mediated suppression of TLR-induced IL-12. Eur J Immunol (2012) 42:2431-40. doi:10.1002/eji.201142360

35. Herrero C, Hu X, Li WP, Samuels S, SharifMN, Kotenko S, et al. Reprogramming of IL-10 activity and signaling by IFN-gamma. J Immunol (2003) 171:5034-41. doi:10.4049/jimmunol.171.10.5034

36. Sharif MN, Tassiulas I, Hu Y, Mecklenbrauker I, Tarakhovsky A, Ivashkiv LB. IFN-alpha priming results in a gain of proinflammatory function by IL-10: implications for systemic lupus erythematosus pathogenesis. JImmunol (2004) 172:6476-81. doi:10.4049/jimmunol.172.10.6476

37. Sozzani S, Bosisio D, Scarsi M, Tincani A. Type I interferons in systemic autoimmunity. Autoimmunity (2010) 43:196-203. doi:10.3109/08916930903510872

38. Platanias LC. Mechanisms of type-I- and type-II-interferon-mediated signalling. Nat Rev Immunol (2005) 5:375-86. doi:10.1038/nri1604

39. Davoodi-Semiromi A, Wasserfall CH, Xia CQ, Cooper-Dehoff RM, Wabitsch M, Clare-Salzler M, et al. The tyrphostin agent AG490 prevents and reverses type 1 diabetes in NOD mice. PLoS One (2012) 7:e36079. doi:10.1371/ journal.pone.0036079 
40. Trivedi PM, Graham KL, Scott NA, Jenkins MR, Majaw S, Sutherland RM, et al. Repurposed JAK1/JAK2 inhibitor reverses established autoimmune insulitis in NOD mice. Diabetes (2017) 66:1650-60. doi:10.2337/db16-1250

41. Turley SJ, Lee JW, Dutton-Swain N, Mathis D, Benoist C. Endocrine self and gut non-self intersect in the pancreatic lymph nodes. Proc Natl Acad Sci U S A (2005) 102:17729-33. doi:10.1073/pnas.0509006102

42. Xing Y, Wang X, Jameson SC, Hogquist KA. Late stages of T cell maturation in the thymus involve NF-kappaB and tonic type I interferon signaling. Nat Immunol (2016) 17:565-73. doi:10.1038/ni.3419

43. Hall JC, Rosen A. Type I interferons: crucial participants in disease amplification in autoimmunity. Nat Rev Rheumatol (2010) 6:40-9. doi:10.1038/ nrrheum.2009.237

44. D'Alise AM, Auyeung V, Feuerer M, Nishio J, Fontenot J, Benoist C, et al. The defect in T-cell regulation in NOD mice is an effect on the T-cell effectors. Proc Natl Acad Sci U S A (2008) 105:19857-62. doi:10.1073/pnas.0810713105

45. Tang Q, Adams JY, Penaranda C, Melli K, Piaggio E, Sgouroudis E, et al. Central role of defective interleukin-2 production in the triggering of islet autoimmune destruction. Immunity (2008) 28:687-97. doi:10.1016/j.immuni. 2008.03.016

46. Monti P, Scirpoli M, Maffi P, Piemonti L, Secchi A, Bonifacio E, et al. Rapamycin monotherapy in patients with type 1 diabetes modifies CD4+CD25+FOXP3+ regulatory T-cells. Diabetes (2008) 57:2341-7. doi:10.2337/db08-0138

47. Skyler JS. Prevention and reversal of type 1 diabetes - past challenges and future opportunities. Diabetes Care (2015) 38:997-1007. doi:10.2337/dc15-0349

48. Wogensen L, Lee MS, Sarvetnick N. Production of interleukin 10 by islet cells accelerates immune-mediated destruction of beta cells in nonobese diabetic mice. J Exp Med (1994) 179:1379-84. doi:10.1084/jem.179. 4.1379

49. Balasa B, Van Gunst K, Jung N, Katz JD, Sarvetnick N. IL-10 deficiency does not inhibit insulitis and accelerates cyclophosphamide-induced diabetes in the nonobese diabetic mouse. Cell Immunol (2000) 202:97-102. doi:10.1006/ cimm.2000.1658

50. Saxena A, Khosraviani S, Noel S, Mohan D, Donner T, Hamad AR. Interleukin-10 paradox: a potent immunoregulatory cytokine that has been difficult to harness for immunotherapy. Cytokine (2015) 74:27-34. doi:10.1016/ j.cyto.2014.10.031

51. Li C, Zhang L, Chen Y, Lin X, Li T. Protective role of adenovirus vectormediated interleukin-10 gene therapy on endogenous islet beta-cells in recent-onset type 1 diabetes in NOD mice. Exp Ther Med (2016) 11:1625-32. doi:10.3892/etm.2016.3169

Conflict of Interest Statement: The authors declare that the research was conducted in the absence of any commercial or financial relationships that could be construed as a potential conflict of interest.

Copyright (c) 2018 Iglesias, Arun, Chicco, Lam, Talbot, Ivanova, Lee, Brandacher and Raimondi. This is an open-access article distributed under the terms of the Creative Commons Attribution License (CC BY). The use, distribution or reproduction in other forums is permitted, provided the original author(s) and the copyright owner(s) are credited and that the original publication in this journal is cited, in accordance with accepted academic practice. No use, distribution or reproduction is permitted which does not comply with these terms. 